\title{
Do Conspiracy Beliefs Form a Belief System? Examining the Structure and Organization of Conspiracy Beliefs
}

\author{
Adam M. Enders ${ }^{1}$, Joseph E. Uscinski ${ }^{2}$, Casey A. Klofstad ${ }^{2}$, Michelle I. Seelig ${ }^{3}$, Stefan Wuchty ${ }^{4,5}$, Manohar N. Murthi ${ }^{6}$, \\ Kamal Premaratne ${ }^{6}$, John R. Funchion ${ }^{7}$ \\ [1] Department of Political Science, University of Louisville, Louisville, KY, USA. [2] Department of Political Science, University of Miami, Coral Gables, FL, USA \\ [3] Department of Cinema and Interactive Media, University of Miami, Coral Gables, FL, USA. [4] Department of Computer Science, University of Miami, Coral \\ Gables, FL, USA. [5] Miami Institute of Data Science and Computing, University of Miami, Coral Gables, FL, USA. [6] Department of Electrical and Computer \\ Engineering, University of Miami, Coral Gables, FL, USA. [7] Department of English, University of Miami, Coral Gables, FL, USA.
}

Journal of Social and Political Psychology, 2021, Vol. 9(1), 255-271, https://doi.org/10.5964/jspp.5649

Received: 2021-01-15 • Accepted: 2021-04-16 • Published (VoR): 2021-06-29

Handling Editor: Lucas A. Keefer, University of Southern Mississippi, Hattiesburg, MS, USA

Corresponding Author: Joseph E. Uscinski, Department of Political Science, 1300 Campo Sano Blvd., 240D Campo Sano Building, Univ. of Miami, Coral Gables, FL 33146, USA. E-mail: uscinski@miami.edu

Supplementary Materials: Data, Materials [see Index of Supplementary Materials]

\begin{abstract}
Despite regular reference to conspiracy theories as a "belief system," few studies have attempted to explore the structure and organization of conspiracy beliefs beyond an examination of correlations between those beliefs. Employing unique data from two national surveys that includes respondent beliefs in 27 conspiracy theories, we decipher the substantive dimensions along which conspiracy beliefs are organized, as well as subgroupings within those dimensions. We find that variation in these conspiracy beliefs can be accounted for with two dimensions: the first regards partisan and ideological identities, while the other is composed of antisocial orientations, such as narcissism, Machiavellianism, psychopathy, and acceptance of political violence. Importantly, these two dimensions are uncorrelated. We also find that conspiracy beliefs group together by substantive content, such as those regarding partisan actors or science/medicine. Our findings also demonstrate that inferences about the correlates of conspiracy beliefs are highly contingent on the specific conspiracy theories employed by researchers. We provide suggestions for future research in this vein.
\end{abstract}

\section{Keywords}

conspiracy theory, ideology, belief system, dark triad, QAnon

The turn of the century has witnessed a resurgence of research into conspiracy theories. In attempting to understand individuals' beliefs in various conspiracy theories, many scholars-beginning with Goertzel (1994)-have conceptualized such beliefs as forming a belief system (see review by Sutton \& Douglas, 2014), an organized web of beliefs. Despite its potential value, the belief system thesis is rarely explored beyond an examination of correlations between conspiracy beliefs (e.g., Goertzel, 1994). While investigations such as this are an obvious starting point, a more direct inquiry would answer additional questions about the substantive qualities of the dimension(s) that organize conspiracy beliefs, the relationships of those beliefs to each other, and the basic principles or content around which conspiracy beliefs are organized-in other words, if and how conspiracy beliefs are structured and organized. Where each of these abstract qualities are well known for other belief systems, such as the liberal-conservative one most prominent in the U.S. (e.g., 
social vs. economic dimensions, attitudes about domestic vs. foreign affairs), there currently exists no analogue for conspiracy beliefs.

The argument that conspiracy beliefs are structured and organized is not only plausible, but theoretically consequential. As Oliver and Wood (2014, p. 13) suggest, treating conspiracy beliefs in this way may offer "new possibilities for the study of political opinion" by illuminating "alternative mechanisms that organize public opinion." If, indeed, beliefs in conspiracy theories form a belief system, scholars would be able to more accurately decipher which conspiracy theories "go together," which types of individuals are likely to believe in specific conspiracy theories, and which dispositions are associated with particular types of beliefs. If conspiracy theories do not showcase the organizational properties and structural characteristics of belief systems, perhaps scholars will need to recalibrate their strategies for studying such idiosyncratic beliefs, as well as those strategies for correcting misinformed beliefs and inoculating individuals to conspiracy theories.

Using survey data collected in March 2020, we examine the structure of beliefs in 20 conspiracy theories, ranging from "birther" beliefs (that Barack Obama faked his birth certificate) to those regarding mass shootings. We use multidimensional scaling (MDS) to investigate the dimensionality and structure of conspiracy beliefs, finding that two dimensions can comfortably account for variability in the conspiracy beliefs we measure. We then examine the substantive structure of conspiracy beliefs. Cluster analysis reveals that conspiracy theories involving similar partisan valence tend to cluster together, as do conspiracy theories involving science/medicine, gross governmental misconduct (e.g., false flag attacks), and small groups (e.g., Rothschilds). An embedding of external psychological orientations into the MDS configuration reveals that partisan and ideological identities constitute one dimension of the cognitive map, which is orthogonal to a second dimension composed of anti-social orientations (e.g., narcissism, psychopathy, and support for political violence). Next, we examine the correlates of (clusters of) conspiracy beliefs, finding that substantive inferences about the potential causes and effects of conspiracy beliefs are heavily contingent on which beliefs are employed. Finally, we replicate and extend our central finding of a two-dimensional structure using an October 2020 survey that includes 16 conspiracy theories; 7 of these-about such topics as QAnon, sex trafficking, and COVID-19-are unique to the second survey.

Our findings advance the study of conspiracy theories in three ways. First, they suggest that the basic dimensionality of conspiracy beliefs is low, organized by a relatively simple psychological structure, just as we would expect of a belief system. Second, our findings demonstrate that not all conspiracy theories are created equal-they vary in important ways even in the minds of a typically disengaged mass public. Finally, our findings demonstrate that conclusions about the basic nature and correlates of conspiracy beliefs are contingent on which conspiracy theories are asked about on surveys. Indeed, some seemingly universal claims about the causes and consequences of conspiracy beliefs may not hold when tested with other sets of conspiracy beliefs and may, therefore, require revision.

\section{Background}

Goertzel (1994) was the first to explicitly suggest that conspiracy beliefs form a belief system. This followed from his observation of highly intercorrelated beliefs in various conspiracy theories; he suggested these correlations were evidence of a "monological" belief system, whereby "...each of the beliefs serves as evidence for each of the other beliefs" (p. 740). In other words, the more conspiracy beliefs one holds, the more likely they are to express belief in other conspiracy theories. At the time of writing, Goertzel's study has been cited 706 times, underscoring the extent to which this idea has taken hold. ${ }^{1}$ However, while researchers have focused on the monological aspect of Goertzel's thesis, little work has focused on the belief system aspect (exceptions include Dagnall, Drinkwater, Parker, Denovan, \& Parton, 2015; Imhoff \& Bruder, 2014). This is despite there being good reason to assume that conspiracy beliefs have organizational properties.

Converse (1964, p. 207) defined a belief system as a "configuration of ideas and attitudes in which the elements are bound together by some form of constraint or functional interdependence." Classical works like Converse's take organization and structure as the foundational characteristics of any belief system (e.g., Stimson, 1975). As such, most

1) According to Google Scholar, as of $4 / 20 / 2021$. 
investigations of belief systems, such as liberal-conservative ideology, begin with an examination of the dimensionality-the interconnectedness-of specific idea-elements. From there, the substantive nature of estimated dimensions is usually examined so that the content of belief systems may be understood.

Take liberal-conservative ideology as an example. Foundational studies examined the correlational structure of issue attitudes, observing fairly low average intercorrelations (what Converse termed "static constraint") and a high dimensional structure relative to political elites (Converse, 1964; Stimson, 1975). In other words, the mass public exhibited less organized beliefs compared to elites, for whom attitudes about specific issues of public policy stem from a single liberal-conservative dimension of political thought. From there, the literature focused on the precise substantive interpretation of the several dimensions underwriting issue attitudes, with studies eventually converging on distinct "social" and "economic" dimensions (Feldman \& Johnston, 2014; Lupton, Myers, \& Thornton, 2015). Of course, the precise number and interpretation of dimensions is contingent on the issue attitudes examined, implying that dimensionality-in number or interpretation-is not completely fixed.

Issue attitudes have also been found to group in important ways within dimensions, with attitudes about domestic and foreign affairs oftentimes being distinct. Others identify "moral" and "racial," or "civil rights," issues as distinct groupings within the social dimension of mass ideology (e.g., Layman \& Carsey, 2002). Importantly, these groupings of issue attitudes-what are oftentimes referred to as issue "domains"-are differentially related to other attitudes and behaviors such as partisanship (Baldassarri \& Gelman, 2008) and even personality traits (Gerber, Huber, Doherty, Dowling, \& Ha, 2010). In other words, substantive inferences about the impact of liberal-conservative ideology on subsequent attitudes and behaviors depend considerably on the issues being used to approximate liberal-conservative ideology.

Investigations into the organization of left-right issue attitudes find only weak analogues in the conspiracy belief literature. Although several studies have examined the factor structure of beliefs in specific conspiracy theories (e.g., Imhoff \& Bruder, 2014), these efforts have usually been in service of building a roughly unidimensional scale for other purposes. $^{2}$ This approach has led to the assertion that the central dimension consistently underwriting conspiracy beliefs is a general predisposition to interpret major events as the product of conspiracies, what most refer to as "conspiracy thinking” or "conspiracy ideation" (Cassese, Farhart, \& Miller, 2020).

One issue raised by the literature, then, is whether conspiracy beliefs can be thought of as forming a conspiratorial belief system (or, the substantive beliefs at the "top" of a belief system, à la liberal-conservative ideology), or whether they are better thought of as the product of a psychological predisposition (i.e., conspiracy thinking), such as authoritarianism, paranoia, or liberal-conservative self-identification instead. ${ }^{3}$ Again using liberal-conservative ideology to draw an analogy, we might say that conspiracy thinking is to liberal-conservative self-identification, as conspiratorial belief systems are to liberal-conservative belief systems. Conspiracy thinking, as a predisposition, is well-evidenced (e.g., Uscinski, Klofstad, \& Atkinson, 2016); however, this does not necessarily support the belief system thesis, as it cannot tell us how or if specific conspiracy beliefs are organized or structured. Still, the literature makes theoretical claims for both a predisposition and a structured belief system despite these constructs being definitionally inequivalent, with predisposition entailing only tendency. Scholars still need to sort out whether conspiracy beliefs can be conceptualized as elements of a distinct belief system or not.

Others have noted the importance of the differences between conspiracy theories (Sternisko, Cichocka, \& Van Bavel, 2020). Usually, distinctions between conspiracy theories hinge on the content of theories. For example, we might distinguish between conspiracy theories accusing partisan actors from those that do not. Previous studies show that individuals tend to believe in conspiracy theories that accuse opposition political parties and their coalitions of conspiring while eschewing conspiracy theories that accuse their own party (Miller, Saunders, \& Farhart, 2016). Despite their intuitive appeal, such distinctions usually constitute a set of assumptions rather than a hypothesis to be tested. Thus, while these and other such distinctions between various conspiracy theories/beliefs are critical to examining the

2) In at least one instance, researchers intentionally used conspiracy beliefs loading on several factors to generate a scale with wide coverage (Brotherton, French, \& Pickering, 2013).

3) Both seem possible simultaneously: people can have a predisposition toward conservative issue positions without exhibiting a high degree of ideological constraint. Our question is whether there is evidence to support the belief system interpretation. 
plausibility of conspiratorial belief systems, there is currently "no reliable typology of conspiracy theories" (Douglas, Sutton, \& Cichocka, 2019, p. 17) or empirically determined sense of "what goes with what" in the minds of the masses.

One consequence is that researchers' ad hoc choices about conspiracy theories may promote discrepancies in the literature, such as those concerning the relationship between conspiracy beliefs and ideology, partisanship, political extremism, and other psychological traits (Imhoff \& Bruder, 2014). For example, the relationship between conspiracy beliefs and predictors like authoritarianism (Oliver \& Wood, 2014; Wood \& Gray, 2019), political ideology/partisanship (Smallpage, Enders, \& Uscinski, 2017; van der Linden, Panagopoulos, Azevedo, \& Jost, 2021), and political extremism (Enders \& Uscinski, 2021; van Prooijen, Krouwel, \& Pollet, 2015) appear to be substantially dependent on which conspiracy beliefs are considered. Understanding the substantive characteristics of a (potential) conspiratorial belief system will not only clarify the major sources of variation within and across conspiracy beliefs, but presumably help guide researchers in selecting the appropriate conspiracy theories to poll on given their research question.

\section{Data and Methods}

An examination of structure in conspiracy beliefs requires estimates of many such beliefs-more than typically employed in single studies. We contracted with Qualtrics to field a questionnaire containing 20 conspiracy belief questions to 2,023 respondents from March 17-19, 2020. Qualtrics partnered with Lucid and Dynata to recruit a sample that matched U.S. Census records on sex, age, race, education, and income. Details about the composition of the sample appear in the Appendix (see Supplementary Materials). ${ }^{4}$

Unfortunately, the literature is bereft of standards governing which conspiracy theories researchers should probe on surveys. This is, first, because there are a near-infinite number of conspiracy theories for people to believe in, owing to the fact that anyone can invent new conspiracy theories or alter existing ones (Uscinski, 2020). Furthermore, the salience and relevance of specific conspiracy theories may vary over time (Uscinski \& Parent, 2014). Therefore, we asked respondents about a broad range of conspiracy theories that vary in their basic topic, the actors accused of conspiring, and their support among visible political elites.

Each of the conspiracy theories we asked about meets the various definitions of "conspiracy theory" proposed in the literature (e.g., Uscinski, 2020) in that they explicitly name or imply a group working in secret, for their own benefit, against the common good, and in a way that undermines bedrock ground rules against the widespread use of force and fraud. While some of the conspiracy theories included may have some "evidence" supporting them, none meet the epistemological threshold for being labeled a "conspiracy" rather than a "conspiracy theory" (Levy, 2007). We also note that, while the "conspiracy theory" label carries cultural baggage, we use the term neutrally and do not imply that any theory is necessarily irrational or false. Rather, these theories have yet to be evidenced by the appropriate epistemological authorities, a standard prescribed by Levy (2007).

The use of large national surveys adds generalizability to our analysis, but also naturally limits the number of conspiracy theories we can ask about. That said, the number of conspiracy beliefs we employ in our initial analysis, 20, is considerably greater than that employed in seminal works on the this topic, such as those by Miller et al. (2016), who employ 8, Oliver and Wood (2014), who use 7, and Goertzel (1994), who employs 10; it is also considerably greater than the number of issue attitudes employed in work on ideological belief systems (e.g., Treier \& Hillygus, 2009). The conspiracy theories we employ appear in Table 1; respondents reacted to each statement using a five-point scale ranging from "strongly disagree" to "strongly agree." The second column of the table contains the percentage of respondents who either "agree" or "strongly agree" with each item. Just as there is considerable variability in the substantive content of the conspiracy theories we employ, there is variability in the level of support the theories receive from the mass public (ranging from 15 to $54 \%$ agreement).

4) As an exploratory effort, our studies were not preregistered, though the replication study was designed to confirm the results of the initial study. The data, code, and other materials necessary to replicate all analyses are available as Supplementary Materials. 


\section{Table 1}

Conspiracy Belief Questions and the Percentage of Respondents Who Agree With Them

1) The one percent (1\%) of the richest people in the U.S. control the government and the economy for their own benefit. (1\%)

2) Jeffrey Epstein, the billionaire accused of running an elite sex trafficking ring, was murdered to cover-up the activities of his

11) The threat of coronavirus has been exaggerated by political groups who want to damage President Trump. (Threat)

There are many analytical strategies for examining structure in multivariate data, such as factor analysis or principal components analysis. Here, we employ multidimensional scaling (MDS). MDS is a family of procedures designed to represent dissimilarities in a set of objects as distances between points in a low-dimensional space, such as a two-dimensional plane. In addition to flexibility with respect to input data, MDS is also better equipped than factor analysis to produce graphical depictions of structure in a dataset. This facilitates interpretation of the conspiracy belief structure, especially pertaining to groupings of conspiracy beliefs and substantive sources of variability. 
It is also important, at this relatively early stage in conspiracy belief research, to employ a methodology designed for exploratory analysis. To be sure, the scientific enterprise should be theory-driven; however, there is some purchase to be gained by letting people tell us how they view conspiracy theories. The division between researchers and subjects is always a difficult one in the context of public opinion, where researchers are tasked with getting into the heads of individuals who spend far less time thinking about politics than they do. This interpretational issue is exacerbated in the context of conspiracy theory research because conspiracy beliefs are often born of anti-scientific and anti-social orientations (Douglas, Uscinski, et al., 2019), which are generally not shared by researchers.

Since the conspiracy belief questions employ ordinal-level scales, we conduct a "nonmetric" MDS, which attempts to model output distances between points as a monotonic (as opposed to linear, had we assumed the data was interval-level) function of input dissimilarities. The dissimilarities are merely the mean Euclidean distances, $\sqrt{\Sigma\left(x_{i}-y_{i}\right)^{2}}$, between each pair of conspiracy beliefs, which are stored in a 20 by 20 matrix of input data. ${ }^{5}$ These and related analyses are executed using the "smacof" package in the R statistical computing environment.

\section{Results}

Two dimensions adequately account for psychological differences/similarities across the 20 conspiracy beliefs we examine. The central criterion for assessing MDS model fit is the STRESS ${ }^{6}$ coefficient, which is a "badness of fit" measure bound between 0 and 1 . Values close to 0 reflect a close correspondence between the input dissimilarities measures and estimated configuration distances (i.e., good model fit). Classical rules of thumb hold that STRESS values below .10 are "good," while those at or below .05 are "excellent" (Borg \& Groenen, 2005). In our case, we achieve a STRESS value of .074 for a two-dimensional solution. This is a vast improvement over a STRESS value of 246 for a unidimensional solution, though we observe only a very minor improvement in fit moving to a three-dimensional solution (STRESS $=.051$ ), especially given difficulties in graphically examining three-dimensional relationships.

Other fit diagnostics also suggest that a two-dimensional solution accounts for the data well. For example, the Spearman rank-order correlation between the input dissimilarities and output interpoint distances is a high .98, and a permutation test produces strong evidence that the low STRESS value we observe is not due to chance $(p<.001)$. We also present a bootstrapped version of the configuration with $95 \%$ confidence ellipses in the Appendix (see Supplementary Materials), which shows that the point configuration is very stable in two dimensions. A well-fitting two-dimensional solution is quite remarkable given that the 20 different conspiracy theories we employ vary in salience, subject matter, and presumably many other attributes.

The two-dimensional configuration appears in Figure 1. Conspiracy theories that are physically proximal are similar in some way, those that distant are dissimilar. Even though a heuristic, visual inspection of the plot appears to make substantive sense, we employ two strategies to aid in interpreting structure in a more systematic way. We begin using hierarchical cluster analysis (HCA).

5) See the Appendix in the Supplementary Materials for a discussion about input data.

6) STRESS stands for STandardized REsidual Sum of Squares. We use the STRESS-1 coefficient: $\sqrt{\frac{\sum\left(d_{i j}-\delta_{i j}\right)^{2}}{\sum d_{i j}^{2}}}$, where $d_{i j}$ are output distances between stimuli $i$ and $j$, and $\delta_{i j}$ are input dissimilarities. 


\section{Figure 1}

Two-Dimensional Nonmetric MDS Configuration

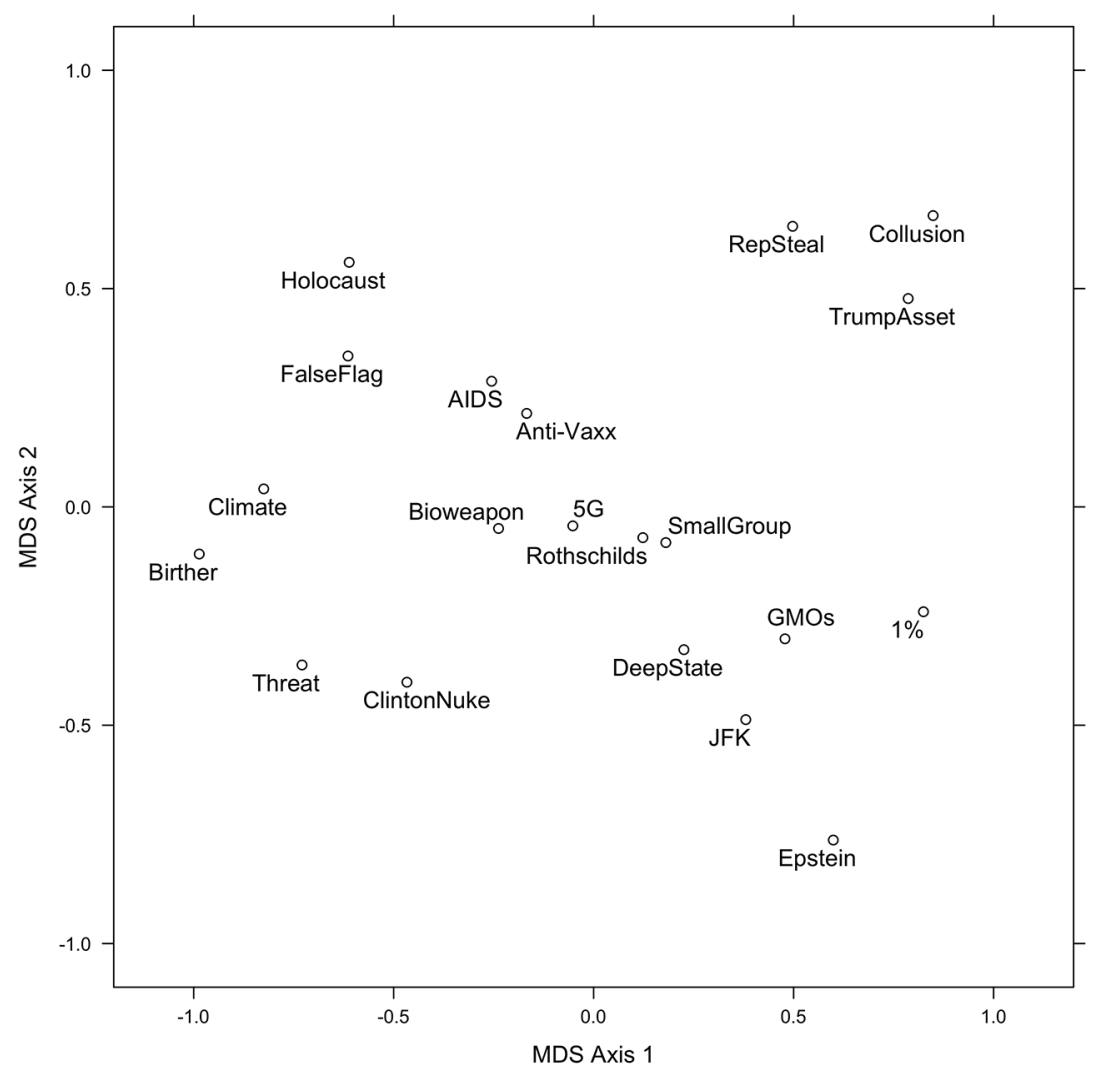

\section{Clusters}

HCA plots the (dis)similarities between objects, according to the Euclidean distance between those objects (here, "as the crow flies" distance between points as measured by the Pythagorean formula), in a tree diagram called a "dendrogram." The agglomerative algorithm we employ ${ }^{7}$ starts by representing the closest objects as the two lowest, closest "leaves" (single objects) at the bottom of the dendrogram. From here, objects are iteratively, hierarchically joined together according to their distance from each other object, from closest to farthest, via branches (i.e., lines that connect individual leaves or groups of leaves).

One byproduct of hierarchical procedures is that the methodology does not inherently identify (the "right" number of) clusters. We are, however, able to partition the tree into clusters using various heuristic devices. One such heuristic involves simply looking at the dendrogram (and MDS configuration) and attempting to visually decipher patterns in the data, as we have already done. This leads to an argument for 4 or 6 clusters. In order to guide our decision in a more analytically rigorous way, we consulted the results of a $k$-means cluster analysis, which revealed that a 6-cluster solution is "best." Partitioning the dendrogram into 6 clusters produces the clusters depicted via the red boxes in Figure 2.

Interpretation of the clusters is straightforward. Starting on the far left on the dendrogram, we observe a cluster of conspiracy theories that find greater support among Republicans than Democrats. This can come in the form of theories that malign Democrats (ClintonNuke, Birther) or their salient issue agendas (Climate), or that explain Republican misfortune (Threat).

7) The "complete linkage" method of agglomeration produces a strong agglomerative coefficient of 0.88 .

8) By "best," we mean a judgement accounting for both parsimony and explanation. See the Appendix in the Supplementary Materials for details. 
Figure 2

Hierarchical Cluster Analysis of Interpoint Distances From Two-Dimensional Nonmetric MDS Configuration With 6 Primary Clusters Identified

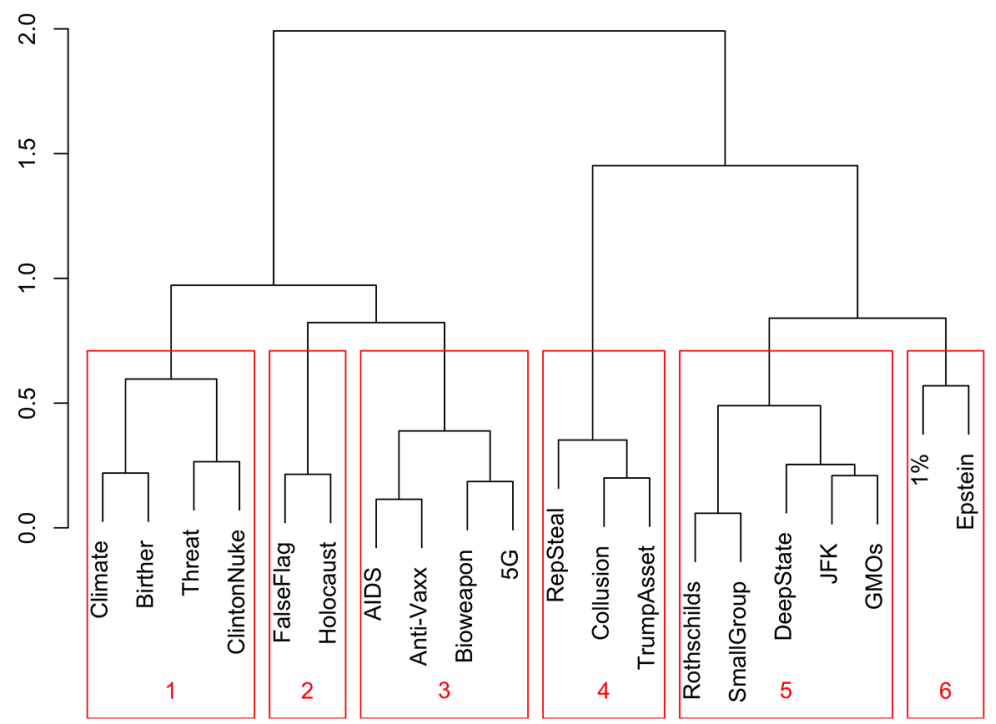

The FalseFlag and Holocaust conspiracy theories compose the second cluster. These two conspiracy theories are unified in finding the least support among respondents. Indeed, these conspiracy theories are both "aggressive," requiring a deep-seated antagonism toward government actors and Jews. The third cluster contains conspiracy theories about science and medicine. The AIDS, Anti-Vaxx, Bioweapon, and $5 G$ conspiracy theories all allege that we are being lied to by companies, the government, or foreign governments about the effects, origins, or cure for various ailments.

The fourth cluster mimics the first in partisan content. In this case, the conspiracy theories in question-Collusion, RepSteal, and TrumpAsset-all malign Republicans, instead of Democrats. As such, Democrats are more likely to believe each of these conspiracy theories than Republicans. The interpretation of the fifth cluster is less straightforward. Each of the conspiracy theories in this cluster receive relatively moderate levels of support. Moreover, four of the five conspiracy theories make allegations about a small group of nefarious actors, whether they be the Rothschilds, the "deep state," or the conspirators behind the murder of JFK. The GMOs conspiracy theory is about science/medicine, but considerably more people believe in the dangers of GMOs than the dangers of $5 \mathrm{G}$ technology or vaccinations.

The final cluster contains the $1 \%$ and Epstein conspiracy theories, both of which received the highest levels of support among respondents ( $50 \%$ or more). The best way to characterize these conspiracy theories is that they are "easy" to believe in: even those with a weak penchant for conspiracy theorizing are likely to put some stock in these ideas. Indeed, some mainstream Democrats regularly speak about the nefarious influences of the 1\%; moreover, the timing of Jeffrey Epstein's death, combined with his high-profile associations, make it particularly suspicious to the masses.

Even though the 20 conspiracy theories we probe in our study vary considerably in their content and structure, they can be broadly categorized into 6 face valid groups. We do not claim to have uncovered "the fixed universal typology of all conspiracy theories." We take one of our initial claims-that the types of conspiracy theories polled can impact substantive inferences- just as seriously as we are asking others to. With more (or different) conspiracy beliefs in one survey, additional groupings may manifest. For example, one could easily imagine a cluster of paranormal conspiracy theories about government cover-ups of alien activity and psychic powers. That said, the groupings that our analysis reveal thus far make substantive sense and, as we will demonstrate below, vary in important ways in their relationships to external criterion variables. Moreover, addition of different conspiracy theories to the analysis does not alter the basic structure uncovered in Figure 1, as we demonstrate in a replication study. 


\section{Dimensions}

Next, we consider substantive dimensions of the MDS configuration. We know that two dimensions are required to accurately explain variability in conspiracy beliefs. We do not, however, know precisely what those dimensions are. Note that the two orthogonal axes labeled "MDS Axis 1" and "MDS Axis 2" need not be substantively interpreted-they constitute an arbitrary coordinate system used to hang the points in two-dimensional space. In order to better understand the substantive dimensions-broad sources of variability-in the MDS configuration, one can regress external variables onto the point coordinates. If these external variables are strongly related to the point coordinates, they can be represented visually in the MDS configuration as new axes (Davison, 1983).

The procedure works as follows. First, external variables are regressed on the point coordinates along the first and second MDS axes. Then, the ratio of slope coefficients associated with the second and first MDS axes can be used to represent the new dimensions corresponding to the external variables within the MDS configuration (Kruskal \& Wish, 1978). We carry out this operation for 7 external variables: partisan identities, ideological identities, psychopathy, Machiavellianism, narcissism, a predisposition to spread false information online, and acceptance of political violence. Each of these factors has previously been found to correlate with conspiracy beliefs of some sort, or directly follow from other known correlates of conspiracy beliefs (Douglas, Uscinski, et al., 2019). Details about the measurement of these constructs-which have been validated previously (e.g., Jonason \& Webster, 2010)-and the regressions used to generate the new dimensions appear in the Appendix (see Supplementary Materials).

Figure 3 depicts the two-dimensional nonmetric MDS configuration with external axes (i.e., colored lines) embedded; the $R^{2}$ values from the external variable regressions appear in the key. Each of the external variables is highly related to the two-dimensional point configuration, exhibiting $R^{2}$ values ranging from .61 (narcissism) to .98 (partisan and ideological identities). To interpret the relationship between each conspiracy theory and these variables, one need merely imagine dropping a perpendicular line from each point to each axis, as we did with the Climate theory. For example, we see that our two clusters of partisan conspiracy theories occupy the poles of the new partisan and ideological identity axes embedded within the configuration, with every other conspiracy theory falling near the center of these left-right dimensions. This not only reinforces the results of the cluster analysis, but additionally underscores that many conspiracy theories have no particular left-right valence, despite some claims that conspiracy theorizing is inherently more prevalent among Republicans and conservatives (e.g., van der Linden et al., 2021). We also find that the FalseFlag and Holocaust conspiracy theories are most strongly associated with psychopathy, Machiavellianism, narcissism, spreading false information online, and supporting political violence. The Epstein, 1\%, and fFK conspiracy theories exhibit the weakest association with these characteristics.

We can also interpret the relationships between the new dimensions by examining the orientation of the new axes toward one another. Geometrically, the correlation between axes is represented by the angular separation between them; acute angles correspond to positive correlations, obtuse angles to negative correlations, and right angles to correlations of 0 . As we might expect, the partisan and ideological axes exhibit almost no angular separation-they are so highly correlated that they are functionally indistinguishable. We also observe very high correlations between psychopathy, Machiavellianism, narcissism, acceptance of violence, and a penchant for sharing false information online. This second set of axes all tend to run in the same direction-one that is roughly orthogonal (i.e., a 90-degree angle) to the partisan and ideological identity axes. In other words, the various external variables reveal two broader substantive dimensions-one dealing with left-right politics, and the other anti-social orientations and behaviors-that are largely unrelated to one another. Not only, then, do left-right political concerns seem to cluster conspiracy beliefs, as seen above, but these concerns seem to constitute a unique dimension that is unrelated to many of the disconcerting psychological predictors of conspiracy beliefs that others have identified. 


\section{Figure 3}

Two-Dimensional Nonmetric MDS Configuration With External Variables Regressed Into the Configuration Space

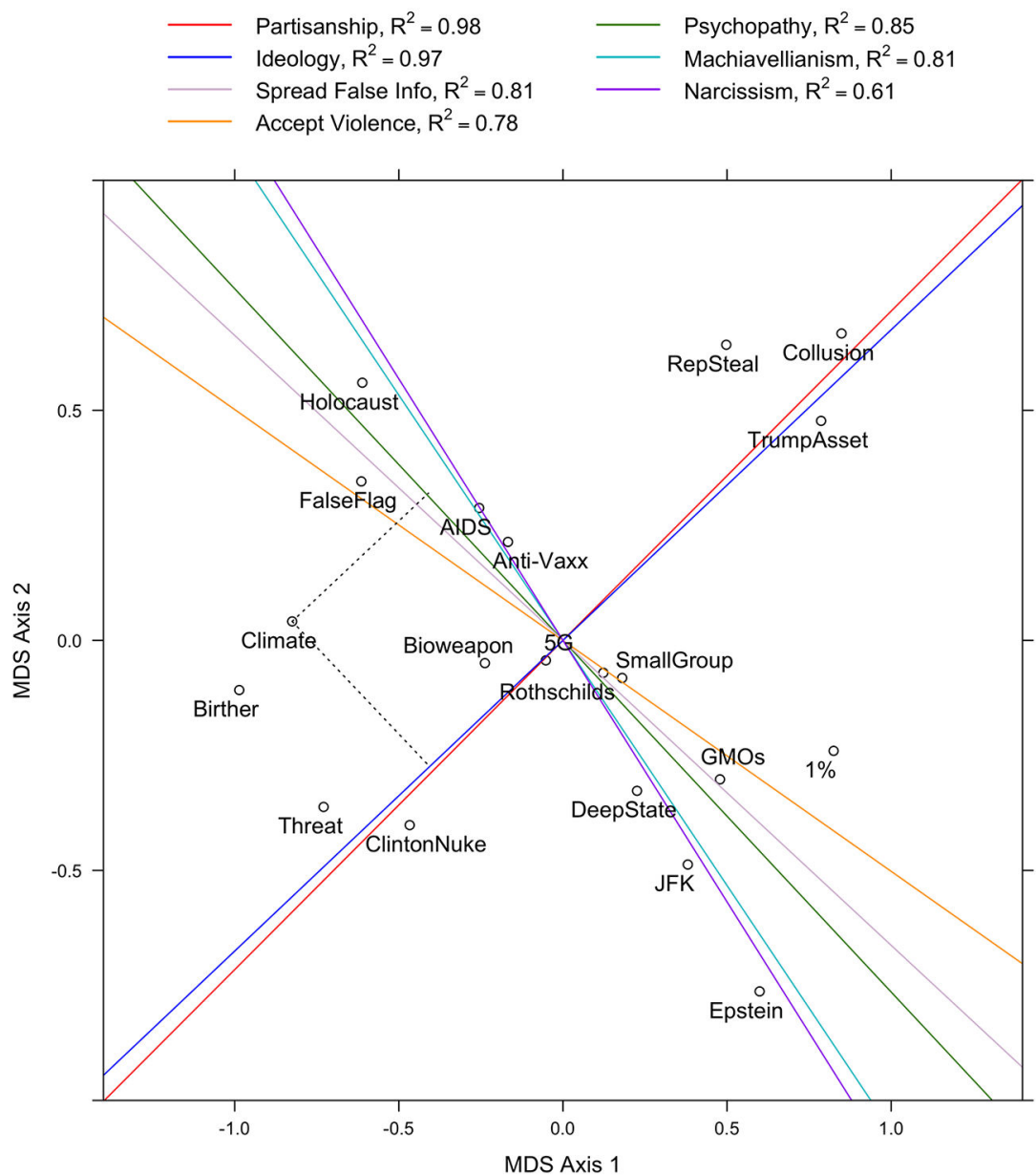

Thus, even though Democrats and liberals, Republicans and conservatives tend to believe conspiracy theories that malign the other side, belief in these conspiracy theories should not be used to infer about the anti-social and "extreme" orientations of their believers (or lack thereof). Conspiracy theories about the Holocaust and school shootings do not merely feel like different kinds of conspiracy beliefs, they are different kinds of beliefs with substantively distinct psychological antecedents.

\section{Consequences}

Even though conspiracy beliefs appear to exhibit the characteristics of a belief system, we know from related research into liberal-conservative belief systems that not all beliefs should be treated identically. Multidimensionality implies that beliefs are distinct in systematic ways. Therefore, our final set of analyses is aimed at examining the extent to which substantive inferences about the characteristics and behaviors of conspiracy believers is contingent on the conspiracy beliefs employed in a given study. To do this, we first generated 6 summated scales of conspiracy beliefs, one corresponding to each of the clusters identified in Figure 2. For example, because cluster 1 contains beliefs in the Climate, Threat, ClintonNuke, and Birther theories, we generate a summated scale of these beliefs; this operation is carried out for the remaining 5 clusters. Next, we regressed various correlates of conspiracy beliefs on each of these scales and host of standard sociodemographic controls for educational attainment, religiosity, age, household income, gender, race, and ethnicity. ${ }^{9}$ 
The quantities of interest are the coefficient estimates associated with the conspiracy belief scales. We are particularly interested in examining the extent to which the estimates vary in strength, sign, and statistical significance. If we observe non-trivial variance in these characteristics across conspiracy belief scales, we will possess evidence that the "type" of conspiracy beliefs employed in a study can impact substantive inferences about the nature of conspiracy belief. If we do not, we can safely assume that conspiracy beliefs can be treated more or less equally.

We estimate 6 regressions for each dependent variable, one for each of the 6 conspiracy belief clusters. The dependent variables we consider are liberal-conservative self-identification, support for Donald Trump, support for Hillary Clinton, conspiracy thinking, support for the QAnon movement, and trust in government. Previous studies find that conspiracy thinking (Miller, 2020b), support for the QAnon movement (Uscinski, Klofstad, \& Stoler, 2020), and (dis)trust in government (Miller et al., 2016) are all related to specific conspiracy beliefs. A long line of literature also suggests that conspiracy beliefs are more prevalent among ideological conservatives (van der Linden et al., 2021). As such, we should expect positive associations between conspiracy beliefs and both conservatism and support for Republican political candidates, like Donald Trump, but negative associations when it comes to liberalism and support for Democratic political candidates, like Hillary Clinton. All variables were rescaled to range from 0 to 1 so that the magnitude of regression coefficients-which appear in Figure 4-can be compared. ${ }^{10}$

\section{Figure 4}

Coefficient Estimates for Each of 6 Cluster-Based Scales, With 95\% Confidence Bands

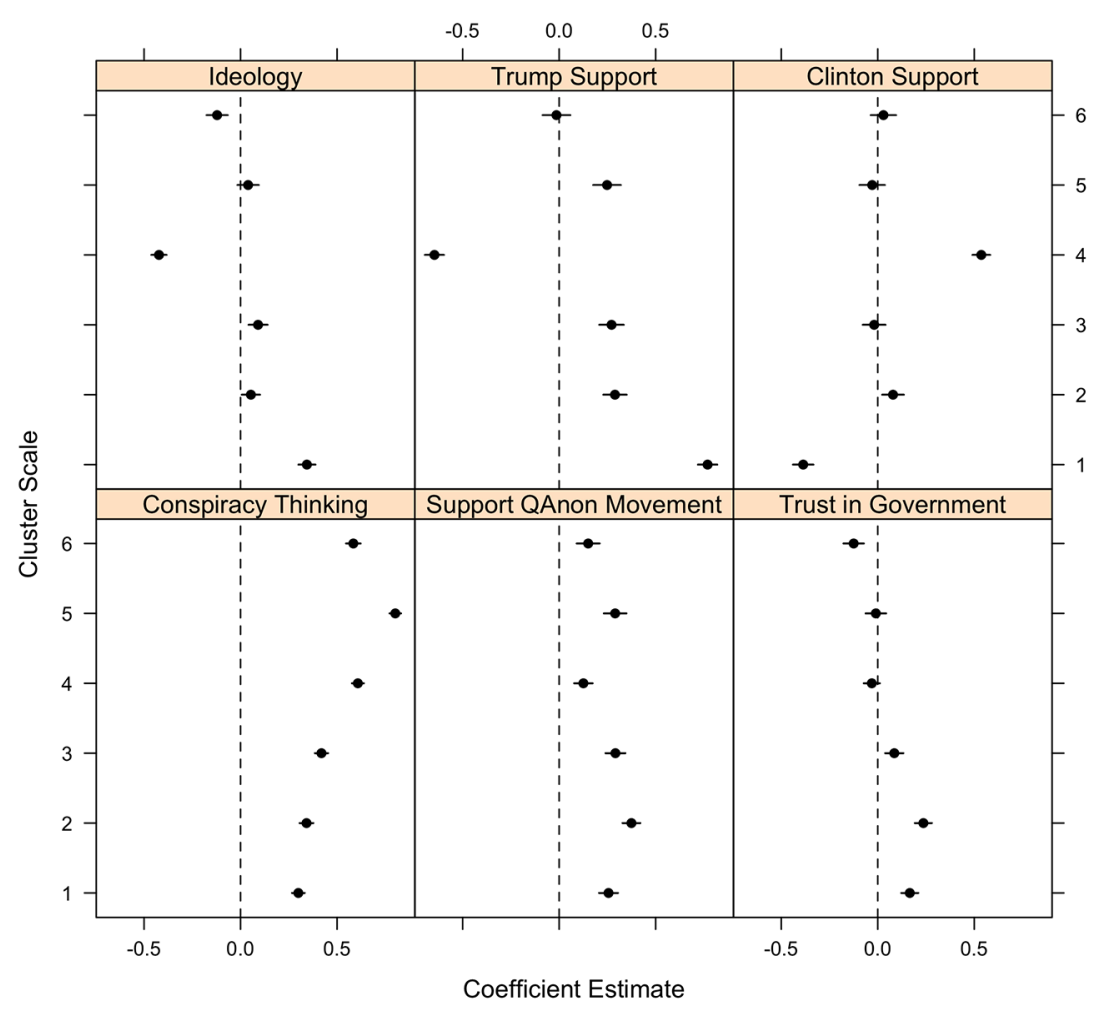

In short, we observe considerable variability in the magnitude and statistical significance of the coefficients associated with the various conspiracy belief scales. Take, for instance, the estimates plotted in the top left ideology panel. Clusters 1 and 4, the Republican/conservative and Democratic/liberal clusters, are significantly related to ideological

9) Note that we cannot and do not make a claim about causality here. Rather, these analyses are simply aimed at demonstrating associational differences.

10) Full regression results appear in the Appendix (see Supplementary Materials). 
self-identification in opposite directions, as we would expect. However, the remaining four clusters exhibit much weaker relationships (the Cluster 5 estimate is not significant at $p<.05$ ), and in opposite directions. Relationships are slightly stronger on average when it comes to Trump support, but the cluster 6 estimate (which includes a conspiracy theory about a Trump associate!) is not significant. We note that these are likely generous estimates-we control for only basic sociodemographic characteristics, intentionally omitting substantive controls one would usually include (e.g., partisanship, psychological orientations). Clinton support is strongly related to the explicitly partisan/ideological Clusters ( 1 and 4 ), and only weakly, positively (contrary to expectations) related to Cluster 2.

What should we make of these patterns? Minimally, the connection between political predispositions and conspiracy beliefs is highly contingent on the content of the conspiracy theories in question. More broadly, inferences about the correlates of conspiracy beliefs are highly contingent on the conspiracy beliefs employed, even for fundamental orientations such as trust in government: Clusters 1,2, and 3 are negatively related to trust in government, but cluster 6 is positively related (counter to expectations) and Clusters 4 and 5 are unrelated.

We do, however, find consistently positive and statistically significant estimates for each cluster when it comes to conspiracy thinking and support for the QAnon movement, despite some variability in the magnitude of estimates. This is not surprising given the overlap in conspiratorial sentiments between these variables and the conspiracy beliefs in each cluster. Yet, it is encouraging that conspiracy thinking is a consistently strong, positive correlate of all manner of conspiracy beliefs. This finding provides supportive evidence that conspiracy thinking-the predispositionnicely mimics liberal-conservative self-identifications in its ability to predict more specific idea-elements (i.e., specific conspiracy beliefs). In short, this variable constitutes an empirically and theoretically justifiable shorthand for the "crowning posture" that characterizes conspiratorial belief systems (Converse, 1964).

\section{Replication and Extension}

Although we do not claim to have uncovered a structure to conspiracy beliefs that always has and will exist in some precise form, we do expect that the structure we find can explain many conspiracy theories that we did not poll on, including those that might appear in the future. To test this proposition, we sought to replicate the MDS results using different conspiracy theories about QAnon, child trafficking, and COVID-19-all popular subjects of conspiracy theories in 2020. If the two-dimensional structure of conspiracy beliefs is a widely applicable one, we should observe that beliefs in these conspiracy theories also fit that structure, and that the dimensions evince the same substantive qualities (e.g., left-right concerns and anti-social personality traits).

We contracted with Qualtrics, who partnered with Lucid, to field a survey to a sample of 2,015 U.S. adults who are representative of the national population in terms of age, sex, race, and education (based on 2010 U.S. Census estimates). We asked about 16 conspiracy theories, 7 of which were not part of the previous analysis. The questions, as well as the proportion of Americans who "somewhat" or "strongly" agree with them, appear in Table A15 of the Appendix (see Supplementary Materials). For the conspiracy theories included in the March data, we include a column denoting the difference between the two polls. We observe stability in the aggregate, just as we would expect of attitudes that are part of a belief system. Thus, during a pandemic in which Americans spent more time online and were inundated with misinformation and conspiracy theories, we do not uncover evidence of a temporal increase in conspiracy beliefs. These findings comport with those of other scholars who also find temporal stability (Romer \& Jamieson, 2020).

We conduct the MDS analysis exactly as we did above, including regressing external factors onto the point configuration to aid in interpreting the substantive dimensions. ${ }^{11}$ As before, a two-dimensional solution fits the data well, achieving a STRESS value of .045 and a Spearman rank-order correlation between input dissimilarities and output distances of .99. The point configuration appears in Figure 5.

11) We do not, however, include attitudes about violence in this analysis. 


\section{Figure 5}

Two-Dimensional Nonmetric MDS Configuration With External Variables Regressed Into the Configuration Space

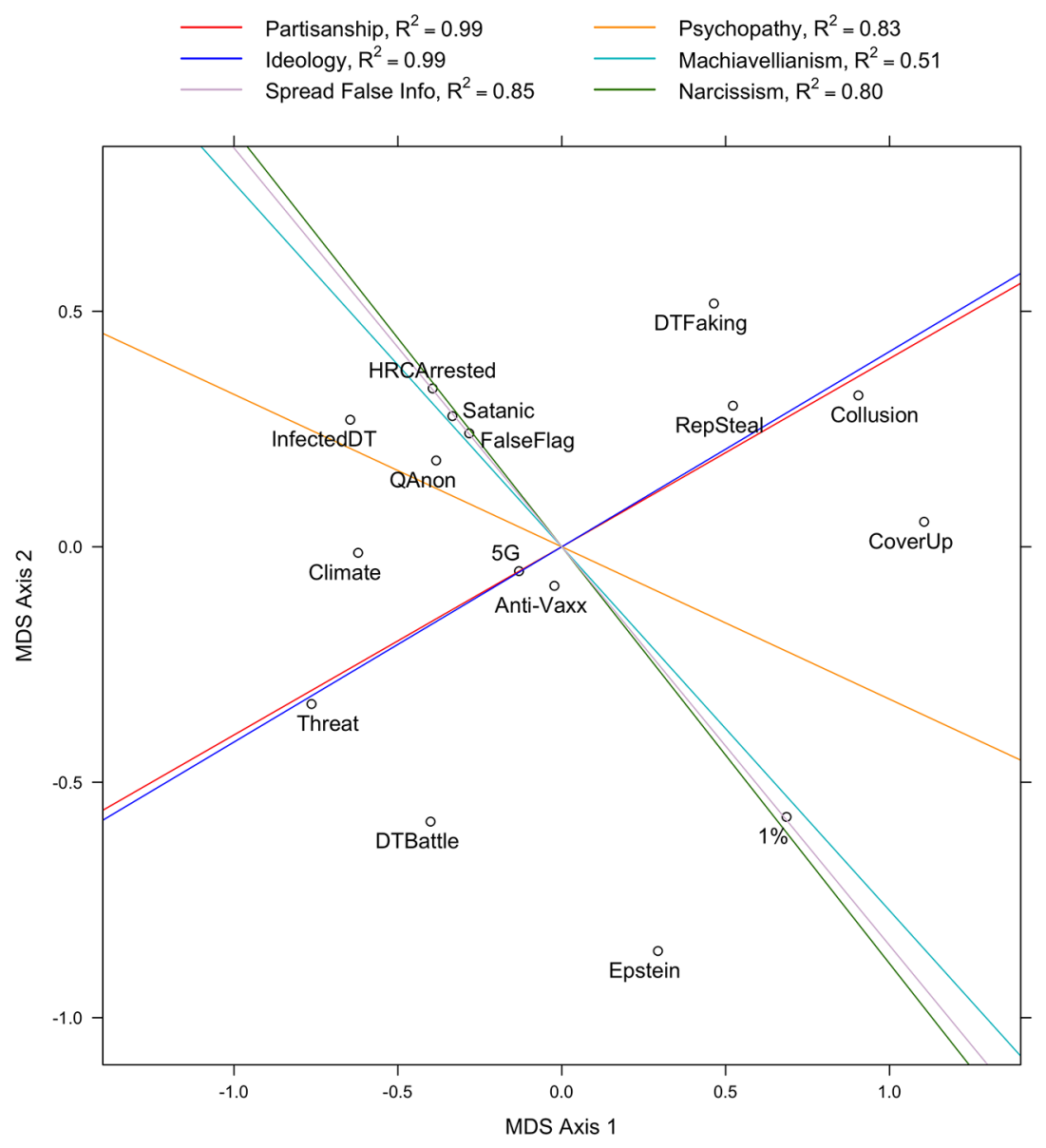

Once again, partisan and ideological identities are situated nearly identically, composing one distinct dimension to the structure of conspiracy beliefs. Beliefs about Donald Trump faking COVID-19 and engaging in a battle against the "deep state," for example, are most related to this dimension. Anti-social personality traits and behaviors-dark triad traits and the predisposition to spread false information online-are also clustered together, roughly forming a second dimension that is orthogonal to left-right concerns. In addition to the FalseFlag belief, beliefs in QAnon, Satan-worshipping governmental elites, and the intentional infection of Donald Trump with COVID-19 are all indicative of anti-social personality traits and behaviors.

\section{Discussion}

Our analyses reveal that there is a coherent, simple structure to conspiracy beliefs. Conspiracy beliefs vary along a low (two, in our case) number of substantive dimensions and group in coherent ways within that low dimensional space-precisely the type of characteristics we would expect of a belief system. In other words, conspiracy beliefs have all the makings of a belief system, at least according to classical definitions (e.g., Converse, 1964). At the same time, conspiracy thinking-the predisposition-is also consistently related to all the different types of conspiracy beliefs we identified. In other words, we can think of conspiracy beliefs as elements of a conspiratorial belief system, but also 
capture the guiding principles of that belief system using the conspiracy thinking predisposition, just as many do with liberal-conservative self-identifications.

We also found that left-right concerns, while a major organizational principle when it comes to many conspiracy beliefs (Miller et al., 2016), are largely unrelated to other substantive dimensions and the conspiracy theories that characterize them. In other words, conspiracy beliefs are not necessarily indicative of believers' anti-social predispositions or undesirable psychological characteristics. While some conspiracy beliefs, like those regarding government false flag events, are related to violent orientations and dark personality characteristics, many are more the product of partisan and ideological motivations and perhaps even elite rhetoric.

This brings us to the first implication for future research: substantive inferences about the causes and consequences of conspiracy beliefs are highly contingent on the conspiracy theories polled on and researchers should be circumspect in how they refer to the beliefs they are examining. If, for instance, one polled on conspiracy theories involving partisan or ideological groups/issues, beliefs should be referred to as "partisan," "ideological" or even "political" conspiracy theories. This labeling has the effect of both appropriately reducing the generality of findings and acknowledging that the content of conspiracy theories matters. Further, researchers should poll on different types of conspiracy theories, generate distinct scales related to these types, and test hypotheses across the various types. Researchers should also consider that the meanings attached to-and the people attracted to-a given conspiracy theory may change over time. For example, 9/11 Truther conspiracy theories found more support among Democrats shortly after 9/11/2001, but have since found more bipartisan support (Enders \& Smallpage, 2018).

Our findings also have implications for the monological belief system thesis (Sutton \& Douglas, 2014). In a monological belief system, the major source of organization-the reason for observed interconnectedness between individual beliefs-is the beliefs themselves. They are self-reinforcing, or as Goertzel (1994, p. 740) put it, "each of the beliefs serves as evidence for each of the other beliefs." However, we find that conspiracy beliefs, while organized, are systematically structured by other predispositions and psychological traits, some of which surely formed before beliefs in the specific conspiracy theories did. While some beliefs may be reinforced by others (Miller 2020a), there also appear to be other sources of constraint present in conspiratorial belief systems (e.g., Moulding et al., 2016). Our findings in this regard are consistent, in many ways, with Franks and colleagues' (2017) qualitative investigation of the dimensionality of conspiracy beliefs. Though they focus more on the understudied, albeit foundational, social (e.g., a sense of community) and epistemological (e.g., nature of reality) reasons why people are attracted to conspiracy theories, they nevertheless demonstrate that conspiratorial belief systems are hardly "closed" and self-reinforcing in the way Goertzel (1994) described. Franks et al.s (2017) findings concerning the importance of in- and out-group identities in promoting conspiracy beliefs are also consistent with our own findings regarding partisan and ideological identities. Future work might consider combining the social and epistemological foci of Franks and colleagues with the more political and psychological focus of our study.

Our study is not without limitations. Our analyses are correlational; therefore, we cannot make causal claims about the relationships highlighted. That said, our central question-about structure and organization-does not necessarily require causal identification. We are also necessarily limited by the number of conspiracy theories we were able to examine. In general, the more the better. However, cost, respondent fatigue, and acquiescence bias are important considerations when conducting surveys. Still, we surveyed the public about a wider range of conspiracy theories than most studies in the conspiracy theory or political ideology literatures, and replication of our results with a new sample and different conspiracy theories provides extra reason for confidence. More data will only bring us closer to understanding which groupings of conspiracy theories are stable over time. This includes application of our framework to non-U.S. samples to see if similar structure, substantive dimensions, and groupings appear in other contexts.

Future work should also investigate how wide-ranging conspiratorial belief systems are. Most people are not (liberal-conservative) ideologues (Kalmoe, 2020), so the standard for what qualifies as a "sufficiently" explanatory belief system is probably weaker than we would prefer from a normative standpoint. That said, it seems likely that conspiracy beliefs are capable of guiding many downstream attitudes and behaviors that are not explicitly related to conspiracy theories, such as political participation (Kim, 2019). Therefore, a conspiratorial belief system could be as important as liberal-conservative ideology for a significant portion of the mass public. In this same vein, future work might further 
consider the stability and durability of conspiracy beliefs (something akin to Converse's concept of dynamic constraint) in order to better understand the properties of conspiratorial belief systems.

Funding: The authors have no funding to report.

Acknowledgments: The authors have no additional (i.e., non-financial) support to report.

Competing Interests: The authors have declared that no competing interests exist.

Data Availability: For this article, a dataset is freely available (Enders, Uscinski, Klofstad, Seelig, Wuchty, Murthi, Premaratne, \& Funchion, 2021a).

\section{Supplementary Materials}

The data, code, and other materials necessary to replicate all analyses are available from the PsychArchives repository (for access see Index of Supplementary Materials below).

\section{Index of Supplementary Materials}

Enders, A. M., Uscinski, J. E., Klofstad, C. A., Seelig, M. I., Wuchty, S., Murthi, M. N., . . Funchion, J. R. (2021a). Supplementary materials to "Do conspiracy beliefs form a belief system? Examining the structure and organization of conspiracy beliefs" [Dataset]. PsychOpen GOLD. https://doi.org/10.23668/psycharchives.4776

Enders, A. M., Uscinski, J. E., Klofstad, C. A., Seelig, M. I., Wuchty, S., Murthi, M. N., . . Funchion, J. R. (2021b). Supplementary materials to "Do conspiracy beliefs form a belief system? Examining the structure and organization of conspiracy beliefs" [Code]. PsychOpen GOLD. https://doi.org/10.23668/psycharchives.4777

Enders, A. M., Uscinski, J. E., Klofstad, C. A., Seelig, M. I., Wuchty, S., Murthi, M. N., . . Funchion, J. R. (2021c). Supplementary materials to "Do conspiracy beliefs form a belief system? Examining the structure and organization of conspiracy beliefs" [Appendix]. PsychOpen GOLD. https://doi.org/10.23668/psycharchives.4930

\section{References}

Baldassarri, D., \& Gelman, A. (2008). Partisans without constraint: Political polarization and trends in American public opinion. American fournal of Sociology, 114(2), 408-446. https://doi.org/10.1086/590649

Borg, I., \& Groenen, P. J. (2005). Modern multidimensional scaling: Theory and applications. New York, NY, USA: Springer Science \& Business Media.

Brotherton, R., French, C. C., \& Pickering, A. D. (2013). Measuring belief in conspiracy theories: The generic conspiracist beliefs scale. Frontiers in Psychology, 4, Article 279. https://doi.org/10.3389/fpsyg.2013.00279

Cassese, E. C., Farhart, C. E., \& Miller, J. M. (2020). Gender differences in COVID-19 conspiracy theory beliefs. Politics \& Gender, 16(4), 1009-1018. https://doi.org/10.1017/S1743923X20000409

Converse, P. E. (1964). The nature of belief systems in mass publics. In D. Apter (Ed.), Ideology and discontent (pp. 164-193). New York, NY, USA: Free Press.

Dagnall, N., Drinkwater, K., Parker, A., Denovan, A., \& Parton, M. (2015). Conspiracy theory and cognitive style: A worldview. Frontiers in Psychology, 6, Article 206. https://doi.org/10.3389/fpsyg.2015.00206

Davison, M. L. (1983). Introduction to multidimensional scaling and its applications. Applied Psychological Measurement, 7(4), 373-379. https://doi.org/10.1177/014662168300700401

Douglas, K., Sutton, R., \& Cichocka, A. (2019). Belief in conspiracy theories: Looking beyond gullibility. In J. Forgas \& R. Baumeister (Eds.), The social psychology of gullibility: Conspiracy theories, fake news and irrational beliefs (pp. 61-76). New York, NY, USA: Routledge.

Douglas, K. M., Uscinski, J. E., Sutton, R. M., Cichocka, A., Nefes, T., Ang, C. S., \& Deravi, F. (2019). Understanding conspiracy theories. Political Psychology, 40(1, Suppl.), 3-35. https://doi.org/10.1111/pops.12568 
Enders, A. M., \& Smallpage, S. M. (2018). Polls, plots, and party politics: Conspiracy theories in contemporary America. In J. E. Uscinski (Ed.), Conspiracy theories and the people who believe them (pp. 298-318). New York, NY, USA: Oxford University Press.

Enders, A. M., \& Uscinski, J. E. (2021). Are misinformation, antiscientific claims, and conspiracy theories for political extremists? Group Processes \& Intergroup Relations, 24(4), 583-605. https://doi.org/10.1177/1368430220960805

Feldman, S., \& Johnston, C. (2014). Understanding the determinants of political ideology: Implications of structural complexity. Political Psychology, 35(3), 337-358. https://doi.org/10.1111/pops.12055

Franks, B., Bangerter, A., Bauer, M. W., Hall, M., \& Noort, M. C. (2017). Beyond “monologicality”? Exploring conspiracist worldviews. Frontiers in Psychology, 8, Article 861. https://doi.org/10.3389/fpsyg.2017.00861

Gerber, A. S., Huber, G. A., Doherty, D., Dowling, C. M., \& Ha, S. E. (2010). Personality and political attitudes: Relationships across issue domains and political contexts. American Political Science Review, 104(1), 111-133. https://doi.org/10.1017/S0003055410000031

Goertzel, T. (1994). Belief in conspiracy theories. Political Psychology, 15(4), 731-742. https://doi.org/10.2307/3791630

Imhoff, R., \& Bruder, M. (2014). Speaking (un-)truth to power: Conspiracy mentality as a generalised political attitude. European Journal of Personality, 28(1), 25-43. https://doi.org/10.1002/per.1930

Jonason, P. K., \& Webster, G. D. (2010). The dirty dozen: A concise measure of the dark triad. Psychological Assessment, $22(2), 420-432$. https://doi.org/10.1037/a0019265

Kalmoe, N. P. (2020). Uses and abuses of ideology in political psychology. Political Psychology, 41(4), 771-793. https://doi.org/10.1111/pops.12650

Kim, Y. (2019). How conspiracy theories can stimulate political engagement. Fournal of Elections, Public Opinion, and Parties. Advance online publication. https://doi.org/10.1080/17457289.2019.1651321

Kruskal, J. B., \& Wish, M. (1978). Multidimensional scaling. Beverly Hills, CA, USA: SAGE.

Layman, G. C., \& Carsey, T. M. (2002). Party polarization and "conflict extension" in the American electorate. American fournal of Political Science, 46(4), 786-802. https://doi.org/10.2307/3088434

Levy, N. (2007). Radically socialized knowledge and conspiracy theories. Episteme, 4(2), 181-192. https://doi.org/10.3366/epi.2007.4.2.181

Lupton, R. N., Myers, W. M., \& Thornton, J. R. (2015). Political sophistication and the dimensionality of elite and mass attitudes, 1980-2004. The fournal of Politics, 77(2), 368-380. https://doi.org/10.1086/679493

Miller, J. M. (2020a). Do COVID-19 conspiracy theory beliefs form a monological belief system? Canadian fournal of Political Science, 53(2), 319-326. https://doi.org/10.1017/S0008423920000517

Miller, J. M. (2020b). Psychological, political, and situational factors combine to boost COVID-19 conspiracy theory beliefs. Canadian fournal of Political Science, 53(2), 327-334. https://doi.org/10.1017/S000842392000058X

Miller, J. M., Saunders, K. L., \& Farhart, C. E. (2016). Conspiracy endorsement as motivated reasoning: The moderating roles of political knowledge and trust. American fournal of Political Science, 60(4), 824-844. https://doi.org/10.1111/ajps.12234

Moulding, R., Nix-Carnell, S., Schnabel, A., Nedeljkovic, M., Burnside, E. E., Lentini, A. F., \& Mehzabin, N. (2016). Better the devil you know than a world you don't? Intolerance of uncertainty and worldview explanations for belief in conspiracy theories. Personality and Individual Differences, 98(1), 345-354. https://doi.org/10.1016/j.paid.2016.04.060

Oliver, J. E., \& Wood, T. J. (2014). Conspiracy theories and the paranoid style(s) of mass opinion. American fournal of Political Science, 58(4), 952-966. https://doi.org/10.1111/ajps.12084

Romer, D., \& Jamieson, K. H. (2020). Conspiracy theories as barriers to controlling the spread of COVID-19 in the US. Social Science \& Medicine, 263, Article 113356. https://doi.org/10.1016/j.socscimed.2020.113356

Smallpage, S. M., Enders, A. M., \& Uscinski, J. E. (2017). The partisan contours of conspiracy theory beliefs. Research \& Politics, 4(4), 1-7. https://doi.org/10.1177/2053168017746554

Sternisko, A., Cichocka, A., \& Van Bavel, J. J. (2020). The dark side of social movements: Social identity, non-conformity, and the lure of conspiracy theories. Current Opinion in Psychology, 35, 1-6. https://doi.org/10.1016/j.copsyc.2020.02.007

Stimson, J. A. (1975). Belief systems: Constraint, complexity, and the 1972 election. American fournal of Political Science, 19(3), $393-417$. https://doi.org/10.2307/2110536

Sutton, R. M., \& Douglas, K. M. (2014). Examining the monological nature of conspiracy theories. In J.-W. v. Prooijen \& P. A. M. v. Lange (Eds.), Power, politics, and paranoia: Why people are suspicious of their leaders (pp. 254-272). New York, NY, USA: Cambridge University Press. 
Treier, S., \& Hillygus, D. S. (2009). The nature of political ideology in the contemporary electorate. Public Opinion Quarterly, 73(4), 679-703. https://doi.org/10.1093/poq/nfp067

Uscinski, J. E. (2020). Conspiracy theories: A primer. New York, NY, USA: Rowman \& Littlefield.

Uscinski, J. E., Klofstad, C. A., \& Atkinson, M. (2016). What drives conspiratorial beliefs? The role of informational cues and predispositions. Political Research Quarterly, 69(1), 57-71. https://doi.org/10.1177/1065912915621621

Uscinski, J. E., Klofstad, C. A., \& Stoler, J. (2020, August 3). Who supports QAnon? Here's what our poll finds. Washington Post. Retrieved from https:/www.washingtonpost.com/politics/2020/08/03/who-supports-qanon-heres-what-our-new-poll-finds/ Uscinski, J. E., \& Parent, J. M. (2014). American conspiracy theories. New York, NY, USA: Oxford University Press.

van der Linden, S., Panagopoulos, C., Azevedo, F., \& Jost, J. T. (2021). The paranoid style in American politics revisited: An ideological asymmetry in conspiratorial thinking. Political Psychology, 42(1), 23-51. https://doi.org/10.1111/pops.12681

van Prooijen, J.-W., Krouwel, A., \& Pollet, T. (2015). Political extremism predicts belief in conspiracy theories. Social Psychological \& Personality Science, 6(5), 570-578. https://doi.org/10.1177/1948550614567356

Wood, M. J., \& Gray, D. (2019). Right-wing authoritarianism as a predictor of pro-establishment versus anti-establishment conspiracy theories. Personality and Individual Differences, 138(1), 163-166. https://doi.org/10.1016/j.paid.2018.09.036 